\title{
Calpain-2 as a Treatment Target in Prenatal Stress-induced Epileptic Spasms in Infant Rats
}

\author{
Hyeok Hee Kwon ${ }^{1,2,4}$, Chiranjivi Neupane ${ }^{1,5}$, Juhee Shin ${ }^{1,2}$, Do Hyeong Gwon ${ }^{1,2}$, \\ Yuhua Yin ${ }^{1,2}$, Nara Shin ${ }^{1,2}$, Hyo Jung Shin ${ }^{1,2,3}$, Jinpyo Hong ${ }^{2,3}$, Jin Bong Park ${ }^{1,3,5}$, \\ Yoon Young $\mathrm{Yi}^{4}$, Dong Woon Kim ${ }^{1,2,3 *}$ and Joon Won Kang ${ }^{1,3,4 *}$ \\ ${ }^{1}$ Department of Medical Science, Chungnam National University, Daejeon 35015, ${ }^{2}$ Department of Anatomy, School of \\ Medicine, Chungnam National University, Daejeon 35015, ${ }^{3}$ Brain Research Institute, School of Medicine, Chungnam \\ National University, Daejeon 35015, ${ }^{4}$ Department of Pediatrics, Chungnam National University Hospital, Daejeon 35015, \\ ${ }^{5}$ Department of Physiology, School of Medicine, Chungnam National University, Daejeon 35015, Korea
}

\begin{abstract}
Stress can induce a serious epileptic encephalopathy that occurs during early infancy. Recent studies have revealed that prenatal stress exposure is a risk factor for the development of infantile spasms. Our previous work demonstrates that prenatal stress with betamethasone-induced alterations to the expression of the $\mathrm{K}^{+} / \mathrm{Cl}^{-}$co-transporter (KCC2) in gamma-aminobutyric acid (GABA) interneurons lowers the seizure threshold in exposed animals. Here, we further investigated the mechanisms involved in this KCC2 dysfunction and explored possible treatment options. We stressed Sprague-Dawley rats prenatally and further treated dams with betamethasone on gestational day 15, which increases seizure susceptibility and NMDA (N-Methyl-D-aspartate)-triggered spasms on postnatal day 15. In this animal model, first, we evaluated baseline calpain activity. Second, we examined the cleavage and dephosphorylation of KCC2. Finally, we checked the effect of a calpain inhibitor on seizure occurrence. The phosphorylated-N-methyl-Daspartate Receptor 2B (NR2B):non-phosphorylated NR2B ratio was found to be higher in the cortex of the prenatally stressed betamethasone model. We further found that the betamethasone model exhibited increased phosphorylation of calpain- 2 and decreased phosphorylation of KCC2 and Glutamic acid decarboxylase 67 (GAD67). After using a calpain inhibitor in prenatal-stress rats, the seizure frequency decreased, while latency increased. GABAergic depolarization was further normalized in prenatal-stress rats treated with the calpain inhibitor. Our study suggests that calpain-dependent cleavage and dephosphorylation of KCC2 decreased the seizure threshold of rats under prenatal stress. Calpain-2 functions might, thus, be targeted in the future for the development of treatments for epileptic spasms.
\end{abstract}

Key words: Epilepsy, Calpain, KCC2, NMDA, Glutamate decarboxylase $67, \mathrm{~K}^{+} / \mathrm{Cl}^{-}$co-transporter

\section{INTRODUCTION}

Received March 30, 2019, Revised May 21,2019,

Accepted July 8, 2019

* To whom correspondence should be addressed. Dong Woon Kim, TEL: 82-42-580-8209, FAX: 82-42-586-4800 e-mail:visnu528@cnu.ac.kr

Joon Won Kang, TEL: 82-42-280-8244, FAX: 82-42-255-3158 e-mail:childlove@cnu.ac.kr
Epilepsy is a common neurodegenerative disorder, remarkably in childhood, and is known to occur in 0.5 to $1 \%$ of patients [1]. A significant factor affecting epileptic spasms and epilepsy is stress [2, 3]. Prenatal stress can affect neuronal development and physiological dysregulation [4] and can alter the secretion of glucocorticoids
Copyright $\odot$ Experimental Neurobiology 2019. www.enjournal.org
This is an Open Access article distributed under the terms of the Creative Commons Attribution Non-Commercial License (http://creativecommons.org/licenses/by-nc/4.o) which permits unrestricted non-commercial use, distribution, and reproduction in any medium, provided the original work is properly cited. 
in the hypothalamic-pituitary-adrenocortical (HPA) axis [5]. We have previously suggested a possible mechanism by which prenatal stress and associated dysfunction of gamma-aminobutyric acid (GABA) interneurons via altered expression of the $\mathrm{K}^{+} / \mathrm{Cl}^{-} \mathrm{co}^{-}$ transporter (KCC2) can contribute to enhanced epileptic spasms in a prenatally stressed betamethasone model [6].

Increased calpain expression has been reported in seizures and epilepsy $[7,8]$. Calpain is a calcium-dependent, non-lysosomal cysteine protease that modifies the structure and regulates the activity of protein targets by limited proteolysis [9]. Calpain activation requires an elevated cellular $\mathrm{Ca}^{2+}$ concentration via the activity of N-Methyl-D-aspartate (NMDA) receptors [10]. Extrasynaptic NMDA receptors activate calpain, leading to cell death $[11,12]$. KCC2 is also known as a substrate of calpain [11].

KCC2 plays critical roles in the generation and maintenance of synaptic plasticity [13] and is involved in neuronal chloride regulation [14]. In immature neurons, it maintains a low intracellular $\mathrm{Cl}^{-}$concentration that forms the basis for the hyperpolarization of the $\mathrm{GABA}_{\mathrm{A}}$ receptor [15]. However, low expression of KCC2 induces high intracellular $\mathrm{Cl}^{-}$concentration and depolarization of the $\mathrm{GABA}_{\mathrm{A}}$ receptor response during development [16].

According to recent reports, KCC2 is related to febrile seizure, idiopathic generalized epilepsy, and infantile spasms $[6,17]$. It has been demonstrated to lead to deficits in neuronal $\mathrm{Cl}^{-}$extrusion capacity. A series of experiments indicated that increased neuronal activity leads to calpain-mediated cleavage of KCC2, resulting in a relief in diffusion constraints and subsequent dispersal of KCC2 clusters [13]. Furthermore, Chamma et al. [13] used a phosphomimetic KCC2 S940D mutant that was found to prevent the activityinduced dephosphorylation-dependent endocytosis and degradation of KCC2.

Here, we use rats primed with the synthetic corticosteroid betamethasone to investigate the relationships between epileptic spasm-associated molecular markers, including calpain activity, total KCC2 protein levels, phosphorylated KCC2 levels, and KCC2 cleavage. By using electrophysiological methods, we further demonstrated that a calpain inhibitor may serve as a target for the treatment of epileptic spasms.

\section{MATERIALS AND METHODS}

\section{Animals}

Pregnant Sprague-Dawley rats purchased from Samtako Bio Korea (Osan, Korea) were housed at $23^{\circ} \mathrm{C}$ under a controlled 12 h:12 h light:dark cycle with light on at 08:00. Food and water were accessible ad libitum. All experiments were carried out with the approval of the Animal Care and Use Committee at Chungnam
National University (CNU-00789) and were consistent with the ethical guidelines of the National Institutes of Health. This study used previously established prenatal maternal stress models [6, $18,19]$. Prenatal betamethasone injection priming was used with postnatal NMDA-triggered spasms. Pregnant rats were randomly divided into two groups of six rats each. Pregnant rats received either intraperitoneal (i.p.) injections of two doses of betamethasone (0.4 mg/kg at 09:00 and 19:00) or vehicle control (normal saline) on gestational day 15 (G15) [18, 19]. Resultant offspring, regardless of sex, were divided into two groups and administered with NMDA (15 mg/kg i.p.) on postnatal day 15 (P15). After NMDA administration, their behavior was observed for $75 \mathrm{~min}$. Spasms were defined by a high degree of flexion (i.e., head and trunk flexion, forelimb, hind limb, and hip flexion). Latency of spasms is the time duration from NMDA injection to the first spasms. We recorded the latency from NMDA administration to the onset of any spasms, as well as the total number of spasms, during this 75 min observation period after NMDA injection.

MDL-28170, a calpain-2 inhibitor was used [11]. Rats received intraperitoneal (i.p.) injection of MDL-28170 (20 mg/kg) or DMSO vehicle twice daily (at 09:00 and 19:00), from postnatal day 7 to 15 .

All studies conducted herein were approved by our institutional animal use committee. Furthermore, the authors considered all guidelines outlined in the ARRIVE guidelines and Basel declaration, including the $3 \mathrm{R}$ concept, when planning these experiments.

\section{Antibodies and reagents}

All commercial antibodies and reagents were purchased from the following sources: NR2A (1:500; AB1555P), NR2B (1:1000; \#06600), KCC2 (1:1000, \#07-432), and GAD67 (1:1000, MAB5406) were purchased from Millipore (Billerica, MA, USA). NR2B-phospho S1303 (1:1000; ab81271) and KCC2-NTD (1:1000, ab107452) were purchased from Abcam (Cambridge, MA, USA). Calpain-1 (1:1000, \#2556S) and calpain-2 (1:1000; \#2539S) were purchased from Cell Signaling Technology (Danvers, MA, USA). KCC2phospho S940 (1:1000; p1551-940) was purchased from Phosphosolutions (Aurora, CO, USA). $\beta$-actin (1:10000, A5316; SigmaAldrich, St. Louis, MO, USA) was used as a loading control. Goat anti-rabbit IgG-HRP (1:5000, \#LF-SA8002) and goat anti-mouse IgG-HRP (1:5000, \#LF-SA8001) were purchased from AbFrontier Co., Ltd. (Seoul, Korea). N-Methyl-D-aspartic acid (NMDA) (M3262) and MDL-27180 (M6690) were purchased from SigmaAldrich.

\section{Western blot analysis}

The whole cortex from each of the P15 pups ( $\mathrm{n}=8)$ of each group 
was dissected and homogenized in PRO-PREP ${ }^{\mathrm{TM}}$ Protein Extraction Solution (iNtRON Biotechnology Inc., Korea). After centrifugation $\left(13,000 \mathrm{rpm}, 15 \mathrm{~min}\right.$ and $\left.4^{\circ} \mathrm{C}\right)$, protein concentrations in the supernatants were determined using Micro BCA protein assay kit (Pierce Chemical, TX, USA) with bovine serum albumin used as the standard. Aliquots containing $30 \mu \mathrm{g}$ of protein were resolved by $8 \%$ or $10 \%$ SDS polyacrylamide gel electrophoresis and transferred onto nitrocellulose membranes. For immunoblotting, membranes were incubated in 5\% skimmed milk prepared in TBS-T (0.1\% Tween-20 in TBS) for $1 \mathrm{~h}$ to block non-specific binding sites, followed by incubation with respective primary antibodies. Membranes were then washed three times for $10 \mathrm{~min}$ each in TBS-T, followed by incubation for $1 \mathrm{~h}$ with respective horseradish peroxidase-labeled secondary antibodies (AbFrontier Co., Ltd.) of 1:5000 dilution prepared in ProNA ${ }^{\mathrm{TM}}$ 5X Phospho-BLOCK Solution (TransLab, Daejeon, Korea). After three further washes, immunolabeled proteins were detected using a SuperSignal enhanced chemiluminescence kit (Pierce Chemical) and ChemiDoc ${ }^{\mathrm{TM}}$ Touch Imaging System (Bio-Rad Laboratories, Inc., Hercules, CA, USA). Three individual samples from the whole cortex at P15 were used for western blot analysis.

\section{Calpain activity assay}

Total nine betamethasone rats and nine control rats were used. The Calpain-Glo Protease Assay (Promega, CA, USA) was used to check the calpain activity in whole cortex lysate $(5 \mu \mathrm{g})$ according to manufacturer's instructions. Protein concentrations were measured using BCA assay kit (Pierce Chemical) with BSA as the standard. Calpain activity was measured by luminoskan ascent luminometer (Thermo scientific).

\section{Electrophysiology and data analysis}

Electrophysiological recordings were obtained from acutely prepared coronal brain slices containing cortical neurons. P14 rats were anesthetized with avertin ( $250 \mathrm{mg} / \mathrm{kg}$, i.p.) (Sigma Aldrich) before decapitation. Brains were quickly separated and coronal hippocampal slices $(300 \mu \mathrm{M})$ were prepared using Vibrotome (Leica VT 1200S; Leica, Germany). Sectioned slices were incubated in artificial cerebrospinal fluid (aCSF) at $34^{\circ} \mathrm{C}$ for $1 \mathrm{~h}$ before use. aCSF consists of $\mathrm{NaCl}(126 \mathrm{mM}), \mathrm{NaHCO}_{3}(26 \mathrm{mM}), \mathrm{KCl}(5$ $\mathrm{mM}), \mathrm{NaH}_{2} \mathrm{PO}_{4}(1.2 \mathrm{mM})$, D-glucose (10 mM), $\mathrm{CaCl}_{2}(2.4 \mathrm{mM})$, and $\mathrm{MgCl}_{2}(1.2 \mathrm{mM})$, pH 7.3 7.4 (300 315 mOsm $\left./ \mathrm{kg}\right)$. Slices were continuously bubbled with mixture of $95 \% \mathrm{O}_{2}$ and $5 \% \mathrm{CO}_{2}$ from the beginning to the end of the recording. Sectioned slices were transferred to the recording chamber continuously perfused with aCSF with flow rate of $3 \sim 4 \mathrm{ml} / \mathrm{min}$ at $32 \sim 34^{\circ} \mathrm{C}$. For perforated patch-clamp recording, gramicidin (Sigma Aldrich) was first dissolved in dimethyl sulfoxide (DMSO) $(3.5 \mathrm{mg} / \mathrm{ml})$ and then diluted to $3.5 \mu \mathrm{g} / \mathrm{ml}$. Patch pipettes were dipped in to the diluted gramicidin and filled with internal solution containing Kgluconate (130 mM), KCl (10 mM), HEPES (10 mM), EGTA (10 $\mathrm{mM}), \mathrm{Mg}^{2+} \mathrm{ATP}(5 \mathrm{mM})$, and $\mathrm{MgCl}_{2}(0.9 \mathrm{mM}), \mathrm{pH}$ 7.3 7.4. Stable holding level obtained after 5 to $10 \mathrm{~min}$ of gigaseal formation corresponds to the resting membrane potential. Series resistance was monitored from the beginning to the end of the experiments. Currents were acquired using Axopatch 200B (Axon instruments, Foster City, CA, USA), filtered at $1 \mathrm{kHz}$, and digitized at $10 \mathrm{kHz}$ (Digidata 1400A, pClamp 10.2 software). Quantitative data are expressed as mean \pm SEM. Student's $t$-test was used for statistical analysis.

\section{Statistical analysis}

We used the NIH image analysis software (ImageJ) to assess immunoblots quantitatively using densitometry detection methods. The statistical analysis of immunoblot was performed using the Mann-Whitney U-test. From animal experiments, resulting quantitative data across the groups were analyzed using analysis of variance (ANOVA). The Newman-Keuls method was used for post-hoc analyses. A p-value of less than 0.05 was considered as statistically significant. All statistical analyses were conducted using the Prism 5.0 software (GraphPad, San Diego, CA, USA).

\section{RESULTS}

\section{Epileptic spasms were triggered by NMDA in the betameth- asone model}

We used a rat model of G15 exposure to betamethasone to investigate NMDA-induced spasms $[6,18,19]$. To determine whether there is a prenatal stress effect on the susceptibility to NMDA-induced spasms, we measured the frequency of spasms and latency to spasms in NMDA-treated P15 rat offspring and in age-matched controls. The limitation of our model is that it does not induce spontaneous spasms. The frequency of spasms was visibly increased in infant rats exposed to betamethasone (mean number in controls \pm SD: $63.17 \pm 13.42$, $\mathrm{p}<0.0001$, mean number in betamethasone-exposed animals \pm SD: $152.83 \pm 40.59, \mathrm{p}<0.0001$ ) (Fig. 1A). In addition, the latency to the onset of spasms was decreased in the betamethasone-exposed animals [mean latency (sec) in controls \pm SD: $1574.67 \pm 234.65$, mean latency in betamethasoneexposed animals \pm SD: $986.17 \pm 289.83$, $\mathrm{p}<0.0001$ ] (Fig. 1B). 
Increased phosphorylation of NMDA receptor $2 B$ and calpain may suggest a role of calpain-2 in the increased susceptibility of spasms

To measure alterations to NMDA receptors in the whole cortex
A

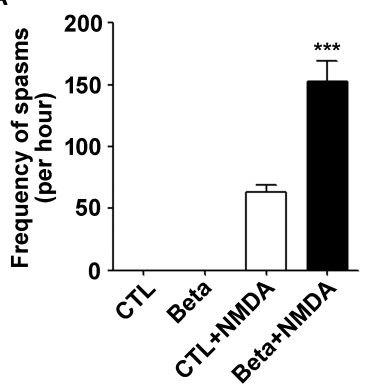

B

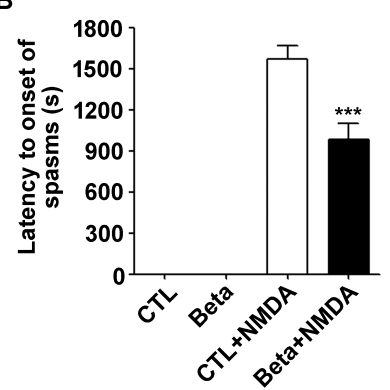

Fig. 1. NMDA-induced spasms were increased in rat offspring following prenatal exposure to betamethasone. Frequency (per hour) (A) and latency (second) (B) to the onset of flexion spasms induced by intraperitoneal NMDA administration were measured in control and betamethasonetreated P15 animals. (A) Frequency of spasms was increased in the offspring prenatally exposed to betamethasone, compared to that in control. (B) Latency to the onset of spasms was decreased in betamethasonetreated P15 animals compared to the control. Statistical significance was assessed by one-way ANOVA. Error bars denote SEM $\left({ }^{* * *} \mathrm{p}<0.001, \mathrm{n}=6\right.$ in each). of betamethasone-exposed rats, we measured levels of NR2A, NR2B, and phosphorylated-NR2B (S1303) proteins (Fig. 2). Increase in $\mathrm{NR} 2 \mathrm{~A}$ and $\mathrm{NR} 2 \mathrm{~B}$ ratio results in maturation and changes of NMDA receptor properties [20]. Levels of NR2A were significantly decreased $(p<0.01, p=0.0022)$ with betamethasone. The phosphorylated-NR2B:non-phosphorylated NR2B ratio in the cortex was significantly increased $(p<0.01, p=0.0022)$ with betamethasone.

In accordance with the increased $\mathrm{Ca}^{2+}$ that might be expected with NMDA receptor alterations, calpain-2 levels were also significantly increased in the whole cortex upon betamethasone treatment (Fig. 3A). However, the level of calpain-1 did not increase (Fig. 3B). We further examined expression of p35/25 (Fig. $3 \mathrm{~B})$. Since cleavage of p35 to p25 induces neurotoxicity, we found significantly increased levels of p25 in betamethasone model rats $(\mathrm{p}<0.01, \mathrm{p}=0.0022)$. Increased calpain-2 in this betamethasone model indicates increased susceptibility to seizures via calpain-2 $(\mathrm{p}<0.05, \mathrm{p}=0.0260)$ (Fig. 3B). The calpain enzyme activity was increased in the betamethasone model rats $(\mathrm{p}<0.05, \mathrm{p}=0.0260)$ (Fig. 3B).
A

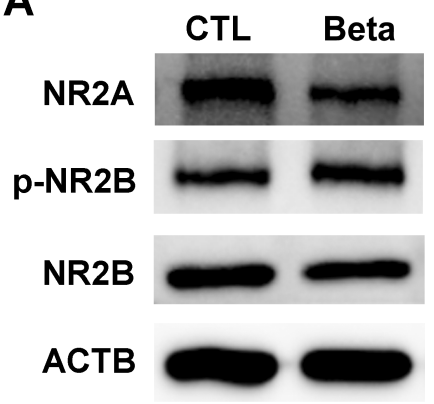

B

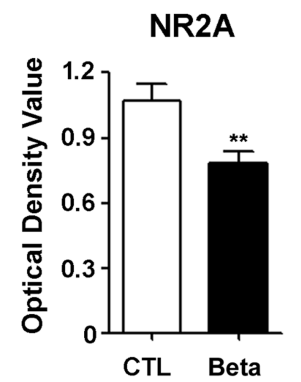

p-NR2B

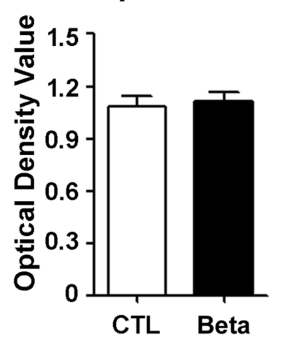

NR2B

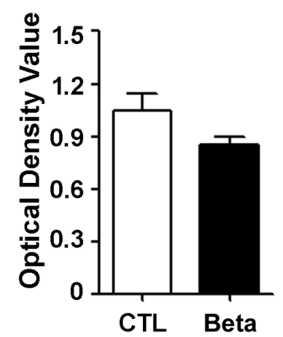

p-NR2B/NR2B

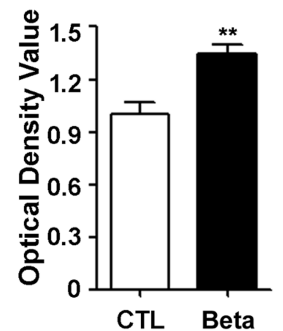

Fig. 2. NMDA receptors in the whole cortex of betamethasone-treated infant rats. The protein level of NMDA receptor 2A was decreased in the betamethasone model. The phosphorylated-NR2B:NR2B ratio was increased upon betamethasone exposure. Statistical significance was assessed using the Mann-Whitney U-test. Error bars denote SEM $\left({ }^{* *} \mathrm{p}<0.01, \mathrm{n}=8\right.$ in each).

A

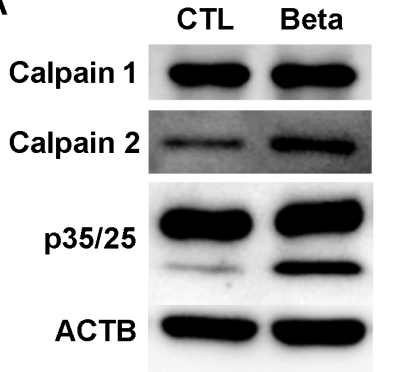

B

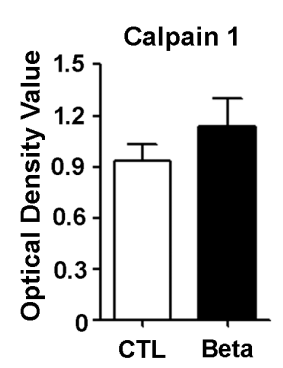

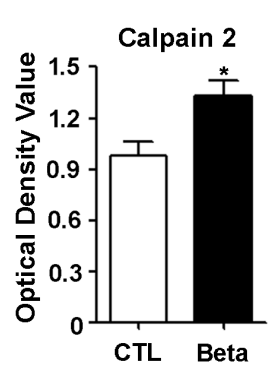

C

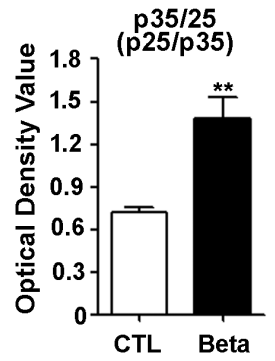

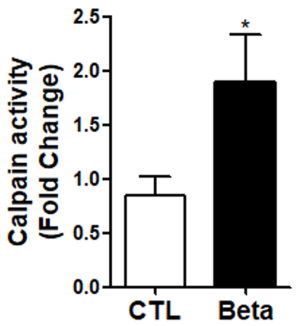

Fig. 3. Calpain-1/Calpain-2 in betamethasone-treated infant rats. Calpain-2 was increased upon betamethasone exposure, whereas calpain-1 was not. p25 levels were increased upon betamethasone exposure. Calpain activity was increased in betamethasone model rats. Statistical significance was assessed using the Mann-Whitney U-test. Error bars denote $\operatorname{SEM}\left({ }^{*} \mathrm{p}<0.05,{ }^{* *} \mathrm{p}<0.01, \mathrm{n}=8\right.$ in each). 
Decreased KCC2 by calpain-2 in the betamethasone model rats

KCC2 is a known substrate of calpain [11]. Given this, we investigated the cleavage of KCC2 by calpain. We measured the level of phospho-KCC2 $(\mathrm{p}<0.01, \mathrm{p}=0.0087)$, total KCC2 $(\mathrm{p}<0.01$, $\mathrm{p}=0.0087)$, and GAD67 $(\mathrm{p}<0.01, \mathrm{p}=0.0022)$ protein expression and found that all protein levels were decreased in the whole cortex of betamethasone model rats (Fig. 4A and 4B). In addition, we found a decrease in protein size due to cleavage of KCC2 (Fig. 4C).

\section{Inhibition of calpain in the betamethasone model rats}

To investigate the effect of calpain-2 inactivation, we applied MDL-28170 (MDL) to our betamethasone model rats $[8,11]$. We measured the latency ( $\mathrm{sec}$ ) to the onset of spasms after cotreatment with MDL in the P15 betamethasone model rats and observed an increased latency to the onset of spasms after this cotreatment (Fig. 5A and 5B). The Frequency of spasms was also decreased in offspring prenatally exposed to betamethasone and betamethasone+MDL compared to that of control group (Fig. 5C).

In addition, reduced KCC2 protein level and increased ratio of p35/25 were recovered in MDL-28170 administration group (Supplementary Fig. 1).

Furthermore, gramicidin perforated-patch clamp recordings were performed in cortical neurons from control, betamethasone, and betamethasone+MDL model rats (Fig. 5D). The mean rest-
A

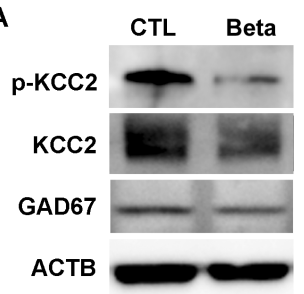

B

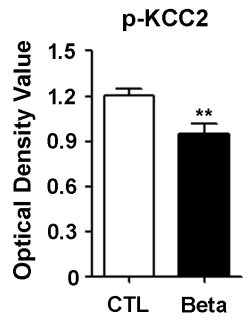

C

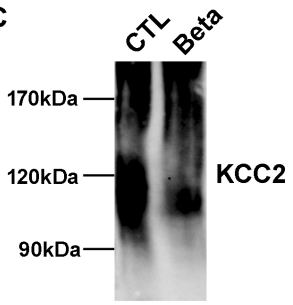

ing membrane potentials $( \pm$ SEM $)$ in control, betamethasone, and betamethasone+MDL models were $-53.63 \pm 1.69 \mathrm{mV},-53.65 \pm 2.36$ $\mathrm{mV}$, and $-57.06 \pm 2.01 \mathrm{mV}$, respectively. Bath application of GABA $(100 \mu \mathrm{M})$ caused significantly larger depolarization of membrane potential in the betamethasone $(8.66 \pm 1.32 \mathrm{mV}, \mathrm{n}=4)$ model com-

\section{A}

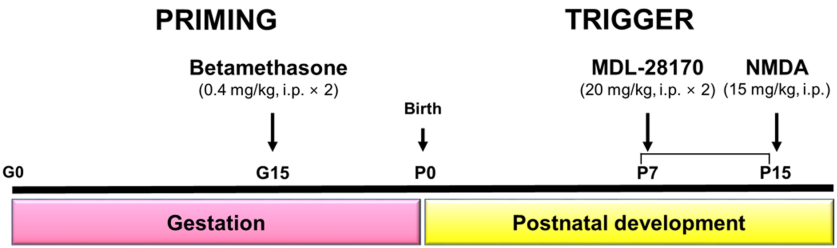

B

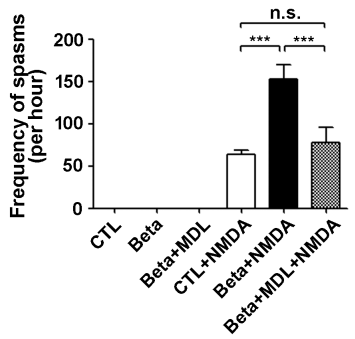

C

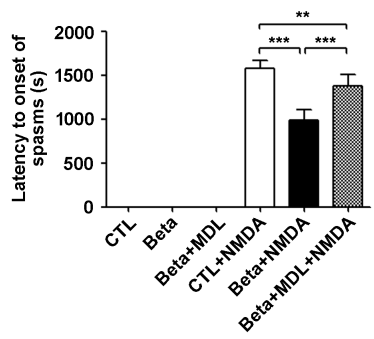

D
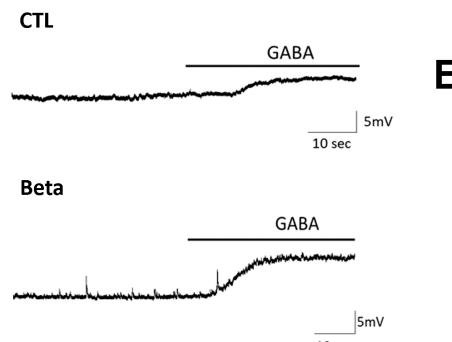

E

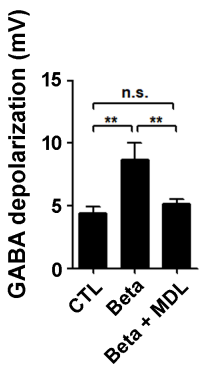

Fig. 5. NMDA-induced spasms in betamethasone and calpain inhibitortreated infant rats. The latency (sec) to the onset of flexion spasms induced by intraperitoneal NMDA was measured in control, betamethasone, and betamethasone+MDL treated P15 rats. The latency to the onset of spasms was increased in the offspring prenatally exposed to betamethasone+MDL compared to that of control and betamethasone group offspring. However, the frequency of spasms was decreased in the offspring prenatally exposed to control and betamethasone+MDL compared to offspring exposed to betamethasone. Statistical significance was assessed by one-way ANOVA. Error bars denote SEM $\left({ }^{* *} \mathrm{p}<0.01\right.$, $\left.{ }^{* * *} \mathrm{p}<0.001\right)$. Representative current traces showing the depolarization of membrane potential by the application of GABA $(100 \mu \mathrm{M})$ in control, betamethasone treated, and betamethasone+MDL treated groups, arranged from top to bottom (D). Summarized bar graph showing mean of depolarization of membrane potential (E). Summarized data are shown as mean \pm SEM $\left({ }^{* *} \mathrm{p}<0.01,{ }^{* * *} \mathrm{p}<0.001\right.$ compared to respective controls, $\mathrm{n}=4 \sim 8$ in each). 
pared to that in control $(4.40 \pm 0.53 \mathrm{mV}, \mathrm{n}=7, \mathrm{p}=0.001)$. In addition, MDL co-treated with betamethasone reversed the membrane depolarization $(5.15 \pm 0.36 \mathrm{mV}, \mathrm{n}=8, \mathrm{p}=0.006$ compare to betamethasone) to almost the control level. These data suggested that infantile spasms induced due to GABA-induced membrane depolarization might be prevented by using an inhibitor of calpain-2 (MDL-28170).

\section{DISCUSSION}

Infantile spasms is an epileptic encephalopathy that occurs in infancy and affects the development of children [21]. While common epilepsy treatment methods are used for it, it often remains intractable [22]. Epilepsy has several known etiologies, but the association between prenatal stress and epilepsy remains poorly understood. Our previous work demonstrated that prenatal stress causes a decrease in KCC2 function in GABAergic interneurons and consequently affects seizure susceptibility in animals [6]. In the present study, we investigated the causes of KCC2 dysfunction and studied treatment methods for targeting this dysfunction in the context of seizure treatment.

In the brain, calpain over-activation is generally found after excitotoxic conditions including physical trauma or a neurochemical challenge [23]. Calpain-mediated cleavage of proteins is required for proper brain function and is a main component of the cellular damage cascade that often follows excitotoxic events $[23,24]$. Calpain activation requires elevated cellular $\mathrm{Ca}^{2+}$ concentration via altered NMDA receptor transport [10]. The extrasynaptic component of the NMDA receptor is composed of a NR1/NR2B subunit. NR2A is highly expressed in synaptic NMDA receptors and NR2B is expressed in extrasynaptic NMDA receptors [25]. The NMDA receptor is also known to be present in GABAergic interneurons and alterations to its activity in these neurons has been associated with brain abnormalities and psychopathology [26]. For example, research on schizophrenia has demonstrated that a functional abnormality in the NMDA receptor affects the function of GABAergic interneurons, possibly leading to disease. Decreased NR2A expression can reduce GAD67 expression and, thus, drive the abnormal development of GABAergic interneurons [27]. Here, we investigated NR2A, NR2B, phospho-NR2B, and GAD67 expression profiles to more closely evaluate the disruption of interneuron systems. In the present study, a reduction of NR2A and GAD67 was also found in prenatally stressed rats, which may in turn affect the function of GABAergic interneurons more broadly. The phosphorylated NR2B:NR2B ratio and calpain-2 level and activity were increased in prenatal stress animals, which we infer is due to elevated cellular $\mathrm{Ca}^{2+}$ concentrations.
Alterations in $\mathrm{Ca}^{2+}$ homeostasis lead to persistent and pathologic over-activation of calpain in a number of neurodegenerative diseases [28]. For example, calpain activation has been found to be excessive in neurological diseases including epilepsy [29-31]. In particular, calpain-specific cleavage of Cyclin-dependent kinase 5 (Cdk5), a proline-directed serine/threonine cyclin-dependent kinase, -p35 to p25 has been implicated in the neurological damage seen in many neurological disorders because they are associated with neuronal migration, synaptic activity, and cell survival and development [32,33]. Calpains have long been implicated in neuronal cell death and injury, including that resulting from excessive excitotoxicity. For example, Putkonen et al. reported that kainicacid (KA) produced a dose-dependent increase in intracellular $\mathrm{Ca}^{2+}$ concentration and calpain activity, followed by the induction of Cdk5 phosphorylation and Cdk-p35 cleavage, which are believed to be involved in KA-mediated degeneration of glutamatergic synapses in the rat hippocampus [34]. Echoing these results, in the prenatal stress model rats examined here, calpain-2 levels were increased, as was the cleavage of p35 to p25.

KCC2 plays a critical role in the generation and maintenance of synaptic plasticity $[7,35]$. For example, it is critically involved in neuronal chloride regulation [36]. In immature neurons, KCC2 maintains low intracellular $\mathrm{Cl}^{-}$concentration, forming the basis for the hyperpolarizing effect of $\mathrm{GABA}_{\mathrm{A}}$ receptors [8]. However, during development, $\mathrm{KCC} 2$ regulates low intracellular $\mathrm{Cl}^{-}$concentration and leads to a depolarizing $\mathrm{GABA}_{\mathrm{A}}$ receptor response [37]. According to the recent reports, KCC2 expression is related to febrile seizure, idiopathic generalized epilepsy, and infantile spasms $[8,38,39]$. Alterations to KCC2 have further been demonstrated to lead to deficits in neuronal $\mathrm{Cl}^{-}$extrusion capacity [6]. Increased neuronal activity leads to calpain-mediated cleavage of KCC2, resulting in a relief in protein diffusion constraints and subsequent dispersal of KCC2 clusters [11,40]. Furthermore, Chamma et al. [13] used a phosphomimetic KCC2 S940D mutant that was found to prevent the activity-induced dephosphorylation-dependent endocytosis and degradation of KCC2.

Our previous work found that KCC2 activity is reduced under prenatal stress. As a result, GABAergic neurons show characteristics of excitation, which lead to increased seizure susceptibility. In this study, we found that the activity of KCC2 is decreased by an increase in calpain. We further found that dephosphorylation and cleavage of KCC2 were increased. In other words, GABAergic neurons were rendered excitatory by the effects of calpain-2. This indicates that calpain may be relevant to potential treatment modalities for seizure.

Many calpain inhibitors have been shown to induce anti-epileptic effects [41]. We assumed here that MDL-28170 could also af- 
fect calpain activity and, therefore, investigated the cleavage of the representative calpain substrate protein in prenatal-stress rats. We found that the prenatal betamethasone exposure-enhanced Cdk5p35 cleavage to p25 was significantly blocked by i.p. administration of MDL-28170. Total number of seizures was decreased and latency to spasms was increased upon MDL-28170 administration. Based on these results, we suggest that a calpain-2 inhibitor produces anti-epileptic effects via calpain inhibition.

One of the limitations of this study is that this betamethasone model does not exhibit spontaneous seizures. However, in other studies that used a similar model, results from EEG and drug response tests were found to be aligned with those for infantile spasms endophenotypes in humans $[39,42]$. Another potential limitation of the present study is that it is difficult to quantify stress accurately. Further studies, using more precise measures of stress levels in animals and humans are, thus, needed to better understand the role of prenatal stress in driving offspring seizure risk.

\section{ACKNOWLEDGEMENTS}

This research was supported by the Basic Science Research Program through the National Research Foundation of Korea (NRF), funded by the Ministry of Science, ICT, and Future Planning (2015R1C1A1A01052351, 2016R1A2B4009409). This work was also supported by Chungnam National University Hospital Research Fund, 2017 (2017-CF-024).

\section{REFERENCES}

1. Sirven JI (2015) Epilepsy: a spectrum disorder. Cold Spring Harb Perspect Med 5:a022848.

2. Maguire J, Salpekar JA (2013) Stress, seizures, and hypothalamic-pituitary-adrenal axis targets for the treatment of epilepsy. Epilepsy Behav 26:352-362.

3. Zhu X, Dong J, Xia Z, Zhang A, Chao J, Yao H (2017) Repeated restraint stress increases seizure susceptibility by activation of hippocampal endoplasmic reticulum stress. Neurochem Int 110:25-37.

4. Maur DG, Romero CB, Burdet B, Palumbo ML, ZorrillaZubilete MA (2012) Prenatal stress induces alterations in cerebellar nitric oxide that are correlated with deficits in spatial memory in rat's offspring. Neurochem Int 61:1294-1301.

5. McGowan PO, Matthews SG (2018) Prenatal stress, glucocorticoids, and developmental programming of the stress response. Endocrinology 159:69-82.

6. Baek H, Yi MH, Pandit S, Park JB, Kwon HH, Zhang E, Kim S, Shin N, Kim E, Lee YH, Kim Y, Kim DW, Kang JW (2016)
Altered expression of KCC2 in GABAergic interneuron contributes prenatal stress-induced epileptic spasms in infant rat. Neurochem Int 97:57-64.

7. Feng ZH, Hao J, Ye L, Dayao C, Yan N, Yan Y, Chu L, Shi FD (2011) Overexpression of $\mu$-calpain in the anterior temporal neocortex of patients with intractable epilepsy correlates with clinicopathological characteristics. Seizure 20:395-401.

8. Puskarjov M, Ahmad F, Khirug S, Sivakumaran S, Kaila K, Blaesse P (2015) BDNF is required for seizure-induced but not developmental up-regulation of KCC2 in the neonatal hippocampus. Neuropharmacology 88:103-109.

9. Lee MS, Kwon YT, Li M, Peng J, Friedlander RM, Tsai LH (2000) Neurotoxicity induces cleavage of p35 to p25 by calpain. Nature 405:360-364.

10. Yu L, Rostamiani K, Hsu YT, Wang Y, Bi X, Baudry M (2011) Calpain-mediated regulation of stargazin in adult rat brain. Neuroscience 178:13-20.

11. Puskarjov M, Ahmad F, Kaila K, Blaesse P (2012) Activity-dependent cleavage of the $\mathrm{K}-\mathrm{Cl}$ cotransporter $\mathrm{KCC} 2$ mediated by calcium-activated protease calpain. J Neurosci 32:1135611364.

12. Zadran S, Bi X, Baudry M (2010) Regulation of calpain-2 in neurons: implications for synaptic plasticity. Mol Neurobiol 42:143-150.

13. Chamma I, Heubl M, Chevy Q, Renner M, Moutkine I, Eugène E, Poncer JC, Lévi S (2013) Activity-dependent regulation of the $\mathrm{K} / \mathrm{Cl}$ transporter KCC2 membrane diffusion, clustering, and function in hippocampal neurons. J Neurosci 33:15488-15503.

14. Wright R, Newey SE, Ilie A, Wefelmeyer W, Raimondo JV, Ginham R, Mcllhinney RA, Akerman CJ (2017) Neuronal chloride regulation via $\mathrm{KCC} 2$ is modulated through a $\mathrm{GABA}_{\mathrm{B}}$ receptor protein complex. J Neurosci 37:5447-5462.

15. Lee H, Chen CX, Liu YJ, Aizenman E, Kandler K (2005) KCC2 expression in immature rat cortical neurons is sufficient to switch the polarity of GABA responses. Eur J Neurosci 21:2593-2599.

16. Lee HH, Deeb TZ, Walker JA, Davies PA, Moss SJ (2011) NMDA receptor activity downregulates KCC2 resulting in depolarizing $\mathrm{GABA}_{\mathrm{A}}$ receptor-mediated currents. Nat Neurosci 14:736-743.

17. Saitsu H, Watanabe M, Akita T, Ohba C, Sugai K, Ong WP, Shiraishi H, Yuasa S, Matsumoto H, Beng KT, Saitoh S, Miyatake S, Nakashima M, Miyake N, Kato M, Fukuda A, Matsumoto N (2016) Impaired neuronal KCC2 function by biallelic SLC12A5 mutations in migrating focal seizures and severe developmental delay. Sci Rep 6:30072. 
18. Chachua T, Yum MS, Velíšková J, Velíšek L (2011) Validation of the rat model of cryptogenic infantile spasms. Epilepsia 52:1666-1677.

19. Yum MS, Chachua T, Velišková J, Velišsek L (2012) Prenatal stress promotes development of spasms in infant rats. Epilepsia 53:e46-e49.

20. Liu XB, Murray KD, Jones EG (2004) Switching of NMDA receptor $2 \mathrm{~A}$ and $2 \mathrm{~B}$ subunits at thalamic and cortical synapses during early postnatal development. J Neurosci 24:88858895.

21. Zhu G, Liu Y, Wang Y, Bi X, Baudry M (2015) Different patterns of electrical activity lead to long-term potentiation by activating different intracellular pathways. J Neurosci 35:621633.

22. Dulac O (2001) What is West syndrome? Brain Dev 23:447452.

23. Liu J, Liu MC, Wang KK (2008) Calpain in the CNS: from synaptic function to neurotoxicity. Sci Signal 1:re1.

24. Curcio M, Salazar IL, Mele M, Canzoniero LM, Duarte CB (2016) Calpains and neuronal damage in the ischemic brain: the swiss knife in synaptic injury. Prog Neurobiol 143:1-35.

25. Benarroch EE (2011) NMDA receptors: recent insights and clinical correlations. Neurology 76:1750-1757.

26. Moreau AW, Kullmann DM (2013) NMDA receptor-dependent function and plasticity in inhibitory circuits. Neuropharmacology 74:23-31.

27. Cohen SM, Tsien RW, Goff DC, Halassa MM (2015) The impact of NMDA receptor hypofunction on GABAergic neurons in the pathophysiology of schizophrenia. Schizophr Res 167:98-107.

28. Araújo IM, Gil JM, Carreira BP, Mohapel P, Petersen A, Pinheiro PS, Soulet D, Bahr BA, Brundin P, Carvalho CM (2008) Calpain activation is involved in early caspase-independent neurodegeneration in the hippocampus following status epilepticus. J Neurochem 105:666-676.

29. Lau A, Tymianski M (2010) Glutamate receptors, neurotoxicity and neurodegeneration. Pflugers Arch 460:525-542.

30. McGeer EG, Zhu SG (1990) Lamotrigine protects against kainate but not ibotenate lesions in rat striatum. Neurosci Lett 112:348-351.

31. Lam PM, Carlsen J, González MI (2017) A calpain inhibitor ameliorates seizure burden in an experimental model of temporal lobe epilepsy. Neurobiol Dis 102:1-10.

32. Kanungo J, Zheng YL, Amin ND, Pant HC (2009) Targeting
Cdk5 activity in neuronal degeneration and regeneration. Cell Mol Neurobiol 29:1073-1080.

33. Nam HY, Na EJ, Lee E, Kwon Y, Kim HJ (2017) Antiepileptic and neuroprotective effects of oleamide in rat striatum on kainate-induced behavioral seizure and excitotoxic damage via calpain inhibition. Front Pharmacol 8:817.

34. Cheung ZH, Ip NY (2012) Cdk5: a multifaceted kinase in neurodegenerative diseases. Trends Cell Biol 22:169-175.

35. Kaila K, Price TJ, Payne JA, Puskarjov M, Voipio J (2014) Cation-chloride cotransporters in neuronal development, plasticity and disease. Nat Rev Neurosci 15:637-654.

36. Ben-Ari Y, Gaiarsa JL, Tyzio R, Khazipov R (2007) GABA: a pioneer transmitter that excites immature neurons and generates primitive oscillations. Physiol Rev 87:1215-1284.

37. Viitanen T, Ruusuvuori E, Kaila K, Voipio J (2010) The $\mathrm{K}^{+}-\mathrm{Cl}^{-}$ cotransporter KCC2 promotes GABAergic excitation in the mature rat hippocampus. J Physiol 588:1527-1540.

38. Jantzie LL, Getsy PM, Firl DJ, Wilson CG, Miller RH, Robinson S (2014) Erythropoietin attenuates loss of potassium chloride co-transporters following prenatal brain injury. $\mathrm{Mol}$ Cell Neurosci 61:152-162.

39. Kahle KT, Merner ND, Friedel P, Silayeva L, Liang B, Khanna A, Shang Y, Lachance-Touchette P, Bourassa C, Levert A, Dion PA, Walcott B, Spiegelman D, Dionne-Laporte A, Hodgkinson A, Awadalla P, Nikbakht H, Majewski J, Cossette P, Deeb TZ, Moss SJ, Medina I, Rouleau GA (2014) Genetically encoded impairment of neuronal KCC2 cotransporter function in human idiopathic generalized epilepsy. EMBO Rep 15:766-774.

40. Puskarjov M, Seja P, Heron SE, Williams TC, Ahmad F, Iona X, Oliver KL, Grinton BE, Vutskits L, Scheffer IE, Petrou S, Blaesse P, Dibbens LM, Berkovic SF, Kaila K (2014) A variant of KCC2 from patients with febrile seizures impairs neuronal $\mathrm{Cl}^{-}$extrusion and dendritic spine formation. EMBO Rep 15:723-729.

41. Putkonen N, Kukkonen JP, Mudo G, Putula J, Belluardo N, Lindholm D, Korhonen L (2011) Involvement of cyclindependent kinase- 5 in the kainic acid-mediated degeneration of glutamatergic synapses in the rat hippocampus. Eur J Neurosci 34:1212-1221.

42. Velišek L, Shang E, Velíšková J, Chachua T, Macchiarulo S, Maglakelidze G, Wolgemuth DJ, Greenberg DA (2011) GABAergic neuron deficit as an idiopathic generalized epilepsy mechanism: the role of BRD2 haploinsufficiency in juvenile myoclonic epilepsy. PLoS One 6:e23656. 